\title{
O sujeito de bicicleta: considerações sobre o discurso cicloativista na São Paulo dos carros
}

\author{
Heloisa Prates Pereira \\ Vinicius Prates
}

Resumo: Neste artigo procuramos identificar um fenômeno discursivo emergente na cidade de São Paulo: o cicloativismo, que passa de um emaranhado de vozes desconexas a uma "fala articulada" no campo de embates sobre os sentidos da mobilidade urbana. O cicloativista constitui-se em uma nova posição de sujeito na medida em que abre um antagonismo ao discurso estabilizado em torno da hegemonia do transporte individual motorizado. O artigo se desdobra em quatro partes: a) uma descrição da cidade voltada ao automóvel como horizonte semanticamente normal; b) a categorização da política como processo de articulação de "falas", nos termos de Rancière; c) a análise discursiva de peças comunicacionais veiculadas em websites especializados em ciclomobilidade; d) considerações sobre um processo de reabsorção parcial da atividade ciclística nas cadeias de equivalência simbólica do liberal-capitalismo.

Palavras-chave: cicloativismo; posições de sujeito; hegemonia; análise discursiva.

Abstract: The cycling subject on the bicicle: considerations on the bike-ativism discourse in the São Paulo of cars - In this paper we intend to identify an emergent discursive phenomenon in the city of São Paulo: the bike activism. It rises from a medley of disconnected voices towards an "articulated speech", in the discursive field about the meanings of the urban mobility. The bike activism constitutes a new subject position insofar as it defies, as an antagonism, the stabilized discourse related to the hegemony of the individual motorized transportation. The paper is divided into four sections: a) a description of the automobile city as a semantically normalized horizon; b) the conceptualization of politics as an articulation of speech, in Rancière terms; c) the discursive analysis of texts published in bike-mobility specialized websites; d) considerations about the partial re-absorption of the cycling into the symbolical equivalence chains of liberal-capitalism.

Keywords: bike activism; subject position; hegemony; discursive analysis. 
São Paulo, sabe-se com precisão, surgiu no dia 25 de janeiro de 1554. Durante o Brasil colônia, sua composição em ruas estreitas e tortuosas, preenchidas por casinhas de taipa de pilão e pau-a-pique, Ihe valeu o apelido de "cidade de barro", "a mud city", segundo um viajante inglês do período (TOLEDO, 1983, p. 13). Esta "primeira" cidade de São Paulo ${ }^{1}$ basicamente ocupou, durante três séculos, o platô que se ergue entre os rios Tamanduateí e Anhangabaú, limites muito para além dos quais não se estendia ainda no final do séc. 19. Foi então que a força econômica do café e de um primeiro surto industrial incipiente lançaram abaixo as paredes de barro socado, abertas aqui e ali em janelões de tábua, para erguer sobre estas ruínas uma cidade "inglesa", de ferro, vidro e tijolos (TOLEDO, 1983, p. 69).

No entanto, a cidade assistiria a uma nova e fantástica rodada de expansão uma vez adentrada a segunda metade do séc. 20. Um longo ciclo econômico industrial de substituição de importações (MIRANDA; TAVARES, 1999) criou as condições para o surgimento de conglomerados privados empresariais nacionais, enquanto o investimento estatal garantia às indústrias de bens de consumo os produtos intermediários necessários à produção. É esta capital de uma região industrializada que mantém até os dias atuais suas principais características: adotou-se o modelo norte-americano baseado no transporte individual por automóveis que acomodava a crescente produção de veículos.

\section{A cidade para os carros}

A cidade sofre sua "terceira transformação" soterrando as linhas de bondes, sucateando o transporte ferroviário intermunicipal de passageiros, tamponando rios e córregos para a criação de autopistas expressas no meio do conglomerado urbano², inclusive com a construção de grandes vias elevadas que cortaram principalmente o centro da cidade. Como resultado dessas alterações viárias, a cidade legada pelo séc. 20 ao séc. 21 é constituída por avenidas implantadas nas baixadas de várzeas e córregos retificados (inundáveis nos meses de chuva); por vias elevadas que cortaram bairros inteiros; por avenidas com leitos carroçáveis desproporcionalmente largos em relação a passeios públicos e outras facilidades para pedestres e ciclistas.

Fazendo-se aqui um paralelo com a descrição de Martin Heidegger (2012a) sobre a construção de uma barragem hidrelétrica no rio Reno, pode-se pensar nesta "terceira São Paulo", como uma cidade que se moldou e se constituiu em sua disposição atual para os carros e pelos carros. Assim como a barragem não mais é um dispositivo construído no Reno, mas o próprio rio é uma engrenagem de sua maquinaria, em São Paulo não são

1 Essa é uma descrição proposta por Benedito Lima de Toledo e hoje muito difundida: "A cidade de São Paulo é um palimpsesto - um imenso pergaminho cuja escrita é raspada de tempos em tempos, para receber outra nova, de qualidade literária inferior, no geral. Uma cidade reconstruída duas vezes sobre si mesma, no último século" (TOLEDO, 1983, p. 67).

2 O "plano de grandes avenidas" de Prestes Maia foi criado ainda nos anos 1930, mas implantado sobretudo ao longo da segunda metade do século (TOLEDO, 1996). 
veículos de transporte que servem às pessoas e trafegam nas ruas, mas há - sim - ruas e todo um aparato de garagens, rotatórias, saídas, autopistas, shopping centers, construídos e adaptados à feição dos veículos.

A cidade de São Paulo foi construída em seu início colonial usando os materiais mais simples que se encontravam disponíveis na própria região (sua própria terra, socada em moldes de tábuas); amoldava-se e respeitava a topografia e a disposição natural dos rios, córregos, colinas e matagais, do território onde estava estabelecida. Um caso diverso é o da cidade dos carros, uma exploração que se impõe à natureza, ou - ainda mais do que isso - que se impõe à velha cidade que respeitava e dialogava com o espaço natural, que se compunha com este espaço: “A usina hidroelétrica não está instalada no Reno, como a velha ponte de madeira que, durante séculos, ligava uma margem à outra. A situação se inverteu. Agora é o rio que está instalado na usina" (HEIDEGGER, 2012a, p. 20).

A São Paulo "velha ponte" tornou-se a São Paulo "usina", desdobrou suas ruas em favor dos automóveis; ela própria passou a ser uma subsidiária da máquina, como uma engrenagem concebida para que os carros pudessem realizar sua vocação dominadora. A pedestres e ciclistas, ou ainda, pessoas com dificuldades de mobilidade, idosos, crianças, animais, artistas de rua, namorados, distraídos, admiradores das copadas das árvores ou da lua cheia, apreciadores de sorvetes no fim da tarde, foi dado o lugar de simples estorvo, de incômodo, de resto a ser eliminado em nome da eficiência da cidade-mecanismo.

\section{Política, discurso, sujeito}

A partir do cenário descrito no segmento anterior, pode-se indagar como, numa cidade que vivenciava uma "normalidade" (PÊUCHEUX, 2006) do transporte individual motorizado, foi possível o surgimento do cicloativista como sujeito político. A política pode ser entendida, a partir de teorias da filosofia contemporânea, como o evento que rompe a normalidade semântica da ideologia vivenciada como realidade, e mostra o caráter contingencial das cadeias de equivalência de um discurso estabilizado. Ernesto Laclau e Chantal Mouffe (2004) entendem a política como processo de disputa por hegemonia, que depende da desarticulação e rearticulação de cadeias de significantes a partir da emergência de um significante mestre, que será colocado no lugar de ponto nodal. São esses pontos nodais que criam as condições para o surgimento de novas posições de sujeitos do discurso.

Jacques Rancière (1996) pensa a questão em termos que podem ser aproximados. De acordo com este autor, a política só pode ser considerada como tal na medida em que novas vozes dissonantes surjam no cenário de disputa. Rancière faz uma distinção entre "voz" e "fala", baseando-se nos clássicos gregos: o homem é o único animal que possui palavra, mas todos os animais têm voz. Eles (os animais) conseguem indicar o sentimento de dor e prazer por sua voz, mas o homem com a palavra, ou seja, por sua 
fala, indica o bem e o mal, o justo e o injusto. A posse do logos, da palavra, manifesta, enquanto a voz apenas indica. A distribuição simbólica dos corpos os divide em duas categorias: "aqueles a quem se vê e a quem não se vê, os de quem há um logos - uma palavra memorial, uma contagem a manter -, e aqueles acerca dos quais não há logos, os que falam realmente e aqueles cuja voz, para exprimir prazer e dor, apenas imita a vOZ articulada" (idem, p. 36). Justamente há política numa situação específica, a que o autor chama de "desentendimento", aquela em que um dos interlocutores ao mesmo tempo entende e não entende o que diz o outro.

Há ainda que se fazer uma referência a Alain Badiou (1994; 2009) e sua teoria do evento quando se busca uma definição de política contemporânea, que o autor atrela à ideia de surgimento do sujeito. Ele entende que o sujeito "não é uma substância, um ser, uma alma, uma 'coisa pensante' como diz Descartes. Ele depende de um processo, começa e acaba" (idem, p. 43). Para Badiou, o sujeito é caudatário de uma verdade, e esta verdade é estabelecida a partir de um evento: "O sujeito não é uma origem. Em particular, não é por haver sujeito que há verdade, mas pelo contrário, porque há verdade há sujeito" (ibidem).

O interesse no estudo do cicloativismo é justamente captar como, ali onde havia um corpo sobre uma bicicleta, sem significado para a política, passa a haver uma posição de sujeito. A partir da articulação do discurso cicloativista, todo corpo humano sobre toda bicicleta será uma expressão política. Se tomarmos como exemplo hipotético um homem que há muitos anos percorre um determinado caminho pedalando, poder-se-ia dizer que este conjunto homem-bicicleta-caminho em determinado momento emerge como o sujeito de uma verdade enunciada por um discurso. A morte de um anarquista nunca é acidental. A morte de um ciclista atropelado por um carro, a partir de sua emergência como sujeito do discurso, é desde já política, e como tal terá desdobramentos.

\section{Análise de três enunciados sobre duas rodas}

Descrevemos São Paulo como uma cidade da hegemonia dos carros (e do antagonismo cicloativista). Certamente ela não é apenas isso: é também a cidade dos shopping centers, a cidade das favelas, a cidade dos bairros operários, dos condomínios fechados, dos sem-teto, da arquitetura corporativa do vidro espelhado. Nenhuma dessas posições pode ser reduzida a outras, e cada uma delas acarreta um recorte sobre o qual se constrói uma posição de sujeito (v.tb. LAZZARATO, 2006, p. 94).

Dentre as possíveis posições de sujeito convocadas por estes diversos discursos sobre a urbanidade que citamos, a do cicloativista parece, à primeira vista, reunir condições para ser especialmente efetiva em sua ex-istência contra-hegemônica. A bicicleta é um objeto que se aproxima mais do campo da manualidade do que o carro, ela "mostra" mais às pernas como pode ser usada como extensão delas, assim como o velho martelo dá-se 
à mão (HEIDEGGER, 2012b, p. 117-118). Na comparação com os carros elas são mais lentas, mais cansativas, expõem mais à chuva, ao vento e ao sol: menos que uma tecnologia, uma velha técnica. Não seria descabido argumentar que há nela certa disfuncionalidade da cidade dromocrática. Seu ser para (idem, p. 116) seria insuficiente, incompetente, aos olhos do Grande Outro carrocrata (mas justamente insistir nesse fracasso criaria um foco de resistência à Lei).

Isto posto, seria possível questionar se há uma pré-disposição nos usos da bicicleta que a torne disposta à subversão. Para tanto é necessário descrever como os ciclistas se tornaram cicloativistas, e suas manifestações passaram de um emaranhado de vozes desconexas a uma "fala articulada" no campo de embates sobre os sentidos da mobilidade urbana. Com base na análise de três enunciados elaborados por diferentes frentes do movimento - um manifesto, uma campanha publicitária e um texto de blog, publicados respectivamente em 2008, 2015 e 2016 - tentaremos compreender esse processo de emergência das falas que constituem novas posições de sujeito.

\section{Análise 1 - Manifesto dos Invisíveis}

O Manifesto dos Invisíveis foi articulado por um grupo de ciclistas e entusiastas da ciclomobilidade em 2008. Fóruns e listas de discussão digitais serviram de suporte para a troca de informações e elaboração de um texto coletivo, subscrito por cerca de 50 pessoas (no ano seguinte outros signatários passaram a se juntar à lista inicial). O manifesto foi elaborado em primeira pessoa do plural, delegando voz ao substantivo coletivo "ciclistas". Os ciclistas são descritos como "cidadãos que utilizam a bicicleta como meio de transporte"; preocupam-se com a saúde e o meio ambiente; asseveram que têm direito de trafegar pelas ruas (as ciclovias seriam apenas uma das maneiras de fazer isso) - mas seu direito não é respeitado:

Não clamamos por ciclovia, clamamos por respeito. As leis de trânsito colocam em primeiro plano o respeito à vida. As ruas são públicas e devem ser compartilhadas entre todos os veículos, como manda a lei e reza o bom senso. Porém, muitas pessoas não se arriscam a pedalar por medo da atitude violenta de alguns motoristas. (MANIFESTO, 2008, online)

Os ciclistas se sentem excluídos pelas políticas públicas ligadas à gestão do trânsito e, segundo eles, a segregação se manifesta em expressões como "a bicicleta atrapalha o trânsito", na sinalização que "quando existe, proíbe a bicicleta", ou na já mencionada violência de motoristas, "uma minoria que assusta e agride". A inclusão da bicicleta como alternativa de mobilidade urbana é euforizada, destacada como uma solução capaz de construir uma cidade melhor. 
O percurso narrativo do manifesto pode ser descrito da seguinte maneira: (1) descontente com os congestionamentos (causado pelo excesso de veículos individuais), o cidadão busca uma alternativa de mobilidade na bicicleta; mas nas ruas, o cenário é perigoso e assustador; (2) os ciclistas precisam perder o medo, por isso, passam a se reunir em grupos; (3) empoderados, colocam em prática seu plano de usar a bicicleta "já"; (4) com o crescimento da ciclomobilidade e, consequentemente, com a visibilidade e a inclusão dos ciclistas nos fluxos do trânsito urbano, o resultado será uma cidade mais humana para todos.

O manifesto, escrito como um documento coletivo para dar voz às demandas dos "ciclistas", tem como enunciador alguém que se inclui nesta posição de sujeito. Os enunciatários pressupostos são outros ciclistas que se identificam com as situações descritas, que compartilham da sensação de isolamento e exclusão verbalizada por seu enunciador. Há um ethos (AMOSSY, 2005) do ciclista que pode ser depreendido a partir do contrato de comunicação que sustenta o texto. Esse sujeito que fala por meio do texto - tal como aqueles com quem ele fala - está cansado de esperar pela "sua vez" no trânsito - pela construção de ciclovias, pela sinalização dos trajetos, pela educação dos motoristas. Ele não quer ser invisível. Ele quer ser contado. O ciclista assume que há um dano (RANCIÈRE, 1996), um erro na divisão dos espaços - e na definição de quem pode circular por eles na cidade.

Inspirados em Rancière, poderíamos dizer que o espaço público da cidade carrocêntrica é dividido entre os diferentes grupos que a povoam - cada qual com sua parcela. A rua está para os motoristas de carros, ônibus e caminhões; a exígua calçada está para os pedestres - ou para que estes consigam chegar até os pontos de acesso ao transporte público; aos ociosos (crianças, idosos, boêmios, vadios) cabem as praças. O ciclista - nem motorista, nem pedestre, nem ocioso - emerge como um sem-parcela, aquele que atrapalha o trânsito, mas que, ao mesmo tempo, afirma que é o trânsito. "Quem não tem parcela - os pobres da Antiguidade, o terceiro estado ou o proletariado moderno - não pode mesmo ter outra parcela a não ser nada ou tudo" (RANCIÈRE, 1996, p. 24).

Vale destacar que o fato novo, neste caso, não é o surgimento de pessoas andando de bicicleta nas cidades. É, sim, a forma de subjetivação proposta pelos ciclistas, materializada no Manifesto, que os conclama a sair da invisibilidade e assumir um papel de protagonismo no enfrentamento dos problemas da mobilidade urbana. Retomemos Rancière: $\mathrm{O}$ ciclista, ao assumir o dano que lhe é causado pelas outras parcelas da sociedade, instaura um litígio. Ele coloca em cheque a distribuição do espaço público, questiona a condição de igualdade entre os cidadãos que andam de carro e os que andam de bicicleta.

Ao final do manifesto, o sujeito coletivo assume sua fala: "nós, ciclistas, que também somos o trânsito". A frase, que se transformou num lema do movimento cicloativista, é sintomática de um novo arranjamento. Para fazer-se visível o ciclista precisa falar como se fizesse parte desde sempre da cena de argumentação na qual os rumos da gestão 
do trânsito são debatidos. Deve colocar-se como interlocutor "como se houvesse um mundo comum de argumentação, o que é eminentemente razoável e eminentemente desarrazoado, eminentemente comportado e eminentemente subversivo, já que esse mundo não existe" (RANCIÈRE, 1996, p. 63). As bicicletadas constituem a realização dessa nova forma de subjetivação. $\mathrm{O}$ ato de reunirem-se para pedalar é uma demonstração de que é como "seres falantes", seres racionais, que os ciclistas pedalam - um ato que pode ser visto e compreendido como tal pelas outras partes do litígio.

\section{Análise 2 - Campanha Bicicleta faz bem ao Comércio}

No ano de 2009, diversos coletivos ligados ao cicloativismo constituíram uma entidade para participar de maneira formal e institucionalizada das deliberações acerca da mobilidade urbana: a Ciclocidade - Associação dos Ciclistas Urbanos de São Paulo. Uma das campanhas da entidade, lançada em 2015, é a campanha "Bicicleta faz bem ao Comércio". Seu objetivo é "orientar e incentivar comerciantes a receberem bem os ciclistas, beneficiando-se do aumento do uso da bicicleta na cidade e das estruturas cicloviárias" (CICLOCIDADE, 2016, online). Um de seus materiais promocionais é o Manual Bicicleta e Comércio. Voltado aos comerciantes de áreas próximas às ciclovias instaladas na cidade de São Paulo, o folder de seis páginas afirma que "ciclistas são os melhores tipos de cliente: ao serem estimulados, voltam com regularidade, gastam mais no mês do que motoristas e o custo para agradá-los é muito baixo" ${ }^{\prime 3}$. No Manual Bicicleta e Comércio, o enunciador adota um tom compreensivo, didático, até professoral. Oferece números ao comerciante, identificando o crescimento da ciclomobilidade como uma tendência mundial.

Este enunciador explica que "Carros não gastam dinheiro. Pessoas sim" (CICLOCIDADE, 2016, online). Busca convencer seu enunciatário de que ele pode se beneficiar com o avanço da bicicleta. Enunciador e enunciatário unem-se, assim, num regime de mesmidade/alteridade (PRADO, 2008) que tem por base o objeto de valor do discurso liberal-capitalista: o lucro. Resta estabelecido um novo ethos, o do empreendedor. Ciclista e comerciante são agora homens de negócios conversando, discutindo, alinhavando um percurso narrativo que pode ser descrito em etapas: (1) o ciclista sabe como fazer o comerciante ganhar dinheiro: para isso acontecer o comerciante deve tornar-se amigo da bicicleta; (2) o comerciante adapta seu estabelecimento para receber ciclistas, demonstrando sua competência gerencial; (3) o comerciante vende seus produtos para o ciclista, que passa a frequentar o estabelecimento e divulgá-lo a seus amigos; (4) o ciclista, ao aprovar o estabelecimento e tornar-se um "cliente fiel", dá sua sanção positiva às ações do comerciante - que por sua vez é recompensado com um negócio mais lucrativo.

3 A campanha tem apoio institucional do Itau Unibanco Holding S/A, o maior banco privado do Brasil, que patrocina diversos programas ligados à ciclomobilidade. 
Trechos do folder evidenciam as tarefas e as vantagens relacionadas à adesão a esse contrato de comunicação:

Diversos estabelecimentos em São Paulo enxergaram a oportunidade e estão se adaptando para receber bem o ciclista. Ao conquistarem fama de "amigos da bicicleta", ganham propaganda no boca a boca e faturam com isso. Oferecer um copo d'água, por exemplo, é sempre gentil, assim como indicar onde fica o lavabo ou o banheiro, para que lavem as mãos. Há também comércios que dão descontos ou brindes para quem chega de bicicleta. (CICLOCIDADE, 2016, online)

A adoção de termos próprios ao campo econômico é outra característica do material da campanha. A ciclomobilidade é uma "tendência das grandes metrópoles"; ciclistas são "novos clientes chegando!" e gastam mais no "acumulado mensal"; comerciantes visionários já "enxergaram a oportunidade" e podem "aumentar seu faturamento". Até mesmo a lógica do custo versus benefício comparece no texto: ciclistas "gastam mais no mês do que motoristas e o custo para agradá-los é muito baixo" (idem).

As diferenças entre ciclistas e motoristas também são amenizadas em prol de um discurso mais complacente, que busca incluir a todos por meio do consumo. "Clientes que chegam de carro e clientes que chegam de bicicleta são diferentes, mas não tanto. Afinal, ambos são consumidores" (idem). Até mesmo as vagas de estacionamento, emblemática da resistência carrocêntrica às ciclofaixas passam por um processo de ressemantização: "Ciclistas, neste ponto, são parecidos a motoristas. Estacionarão onde sentirem que é seguro e, sempre que possível, o mais próximo de onde querem ir" (idem).

No Manual Bicicleta e Comércio, a subjetivação militante do ciclista é sobreposta por outra, integrada ao discurso liberal-capitalista, a do consumidor. Aquilo que era antagonismo, uma posição de enfrentamento, de contraposição à uma cidade do carro que remete não somente à indústria automobilística mas também a toda uma configuração do urbano materializada em avenidas, estacionamentos e shopping centers - passa a ser ressignificado, amainado como um novo nicho de mercado: ele pode se tornar visível, basta aceitar a convocação e inserir-se na cidade como consumidor; afinal "ciclistas usam um veículo prático, simples e rápido, então podem voltar mais vezes para fazer compras" (CICLOCIDADE, 2016, online).

\section{Análise 3 - Texto do site Bike é Legal}

O terceiro material de análise é o artigo "A professora bicicleta: 10 lições de vida que a bike nos ensina", de Ricardo Gaspar, publicado no site Bike é Legal. Dedicado a temas como ciclismo, mobilidade urbana e sustentabilidade, o espaço foi idealizado pela jornalista e ícone do cicloativismo Renata Falzoni. É alimentado regularmente "com notícias, vídeos, fotos, artes, ideias, questionamentos, discussões e reivindicações"; 
seu texto auto-descritivo informa que "o site reúne ciclistas que são referências sobre o tema no Brasil" (BIKE, 2016, online). Esta iniciativa também conta com patrocínio oficial do Itau Unibanco Holding S/A.

O artigo selecionado foi publicado em abril de 2016 e também compartilhado em mídias sociais. Nesse texto, que busca divulgar a cultura da bicicleta, o enunciador assume uma posição de saber em relação a seu enunciatário: ele pode dizer ao não-ciclista o que fazer para conquistar atributos valorizados como "controle emocional":

O que a bicicleta pode nos ensinar? Além de a bicicleta ser uma forma de lazer e mobilidade muito interessante, ela nos traz, durante o uso mais frequente ou durante provas e passeios, uma série de ensinamentos e lições para usarmos no dia a dia e no nosso controle emocional. Irei listar algumas que aprendi pedalando. (BIKE, 2016, online)

O percurso narrativo pode ser assim descrito: (1) o ciclista convoca seu enunciatário a aprender com a bicicleta; (2) este, por sua vez, deve tornar-se ciclista e, com a bike, (3) aprender a "controlar a ansiedade", "se organizar", "superar obstáculos", entre diversas outras lições. Se desempenhar bem essas ações, poderá conquistar seu objeto de desejo e (4) dominar suas emoções.

As lições a serem aprendidas são dez: acreditar em si mesmo, desenvolver a autoestima, controlar a ansiedade, se organizar, descobrir o próprio ritmo, contemplar a paisagem, aceitar os problemas, se satisfazer com as suas conquistas, ter paciência e ajudar o próximo. Todas elas dependem exclusivamente do enunciatário - das ações realizadas por ele em prol do próprio aprendizado. Esse mapa cognitivo (PRADO, 2011) serve de guia para o processo de tornar-se um sujeito equilibrado, assumindo um modo próprio de ser, estar e sentir a cidade. E o centro desse processo recai no competente gerenciamento biopolítico do corpo (FOUCAULT, 2008).

A primeira lição, no estilo "se você quer, você pode", lembra os livros de autoajuda: "Quando você vê alguém pedalando e se questiona se você também conseguiria andar de bicicleta na cidade, pedalar $50 \mathrm{~km}$ ou fazer uma prova, eu garanto que sim. Só começar, tudo na vida é assim.". Em seguida, o enunciador destaca a importância do autocontrole, da disciplina, e lembra que "A evolução e melhoria é conseguida pouco a pouco, a medida que você for estabelecendo pequenos desafios e se dedicando para isso.". E o texto segue, oferecendo uma série de "aprendizados" capazes de fazer com que o enunciatário consiga controlar suas emoções e obter satisfação pessoal.

\section{Considerações finais}

A partir das análises, pode-se considerar que a disputa sobre os sentidos do uso das bicicletas em São Paulo se dá em dois movimentos principais: a) num primeiro momento, 
o cicloativismo emerge identificando-se de maneira política, criando aquilo que Žižek (1999, p. 15) chama de "ideologia como complexo de ideias", uma posição de sujeito que se autoafirma, e descreve a si mesma como participante da luta por hegemonia em um determinado campo discursivo. Este é o cicloativismo que produz um manifesto, colocando-se politicamente como posição minoritária na São Paulo dos carros, como vimos; b) já num segundo momento há um amainamento dessa posição mais propriamente contestadora que havia emergido com o manifesto de uma década atrás. O cicloativista, que se diferenciava do entorno automobilístico por um vivo antagonismo, integra-se na circunvisão da cidade, apaziguado.

O cicloativista pode participar do campo da mesmidade razoável da cidade carrocêntrica no momento em que é, por assim dizer, enovelado nos fios e tramas de uma série de outras posições de sujeito. Diante da oposição aos carros, São Paulo torna-se a cidade da cultura, da saúde, da liberdade individual, da agilidade para driblar as calçadas, as escadarias, a cidade que volta a valorizar o seu centro, a cidade das artes e do convívio. Como diz Badiou (1994, p. 13), a única universalidade do capitalismo é o capital - nisso há bastante solidez. O enunciador cicloativista que se posiciona de forma antagônica à cidade dos carros recebe de volta convocações da cidade das compras e dos shoppings, das oportunidades imobiliárias, dos passeios e diversões, dos esportes e do fitness etc. Ao aproximar-se de instituições tradicionalmente alinhadas ao discurso hegemônico do liberal-capitalismo (tais como bancos e financeiras), este enunciador elide o antagonismo direto de suas manifestações.

O protagonismo empresarial - soluções desenvolvidas ou subsidiadas pela iniciativa privada em parceria com a gestão pública - criou aquilo que Carlos B. Vainer chama de cidadeempresa. O autor ironiza os pressupostos do market lead city planning da seguinte maneira:

Como assegurar que a cidade-empresa, planejada e gerida estrategicamente como uma empresa, alcance a eficácia, isto é, a produtividade e a competitividade que se esperam de uma empresa? A melhor solução, aqui como em outras situações similares, é recorrer a quem entende do métier - se de empresa se trata, convoquem-se os empresários, se o assunto é business, melhor deixá-lo nas mãos de businessmen. (VEINER, 2012, p. 87)

Assim, quando a cidade mostra-se ineficiente, travada por carros estáticos em avenidas congestionadas, a iniciativa privada do grande capital surge como agente da transformação. O incentivo a novos modais de transporte urbano - a bicicleta entre eles - se materializa em parcerias com a prefeitura ${ }^{4}$; no financiamento de projetos e campanhas idealizados por coletivos de ciclistas e por associações como a Ciclocidade; no patrocínio de sites e blogs voltados ao tema.

4 Uma destas iniciativas é o já mencionado Bike Sampa: projeto de compartilhamento de bicicletas realizado pela Prefeitura de São Paulo através da Secretaria Municipal de Transportes, em parceria com o Itaú Unibanco e com a Samba/Serttel. Bicicletas são disponibilizadas para a população por 30 minutos, gratuitamente, para a realização de trajetos curtos. Devem ser retiradas e devolvidas em estações distribuídas pela cidade. 
Os formuladores do discurso hegemônico, ao euforizar essas iniciativas, realizam uma operação de incorporação do Outro cicloativista, trazendo-o para uma posição mais condizente com o Mesmo consumidor, mudando-se os sentidos da própria cidade. Não há dificuldade na cidade de concreto em mostrar-se líquida, claro, desde que com algum "banho de loja" semiótico. E esta releitura traz alguns traços que muito bem podem passar a homologar o liberal-capitalismo no hábito de pedalar. A atividade ciclística passa a significar, por exemplo, o cuidado de si. O uso da bicicleta torna o corpo - este corpo que desde antes da doença padece com sua simples possibilidade - mais magro e mais saudável, mais ativo e mais produtivo.

Ainda talvez mais importante como estratégia de assimilação a partir da homologação dos objetos de valor dominantes, está a maleabilidade com a qual a bicicleta se incorpora aos fluxos, como diria Deleuze (2010). Ela não vai mais contra a rua, contra os carros, mas se amolda, se adapta. A bicicleta passa a ser ressignificada como "fluida", é aquela capaz de entrar pelos meandros, desviar-se, ser ágil para saltar de uma via carroçável para uma calçada, voltar a uma via exclusiva para pedestres, entrar eventualmente em um transporte público, guardar-se dependurada com facilidade, e assim por diante. Quem sabe, ser até mesmo mais rápida do que os carros pesadões parados em congestionamentos...

Perguntamos se a bicicleta, como um objeto técnico, guardaria em si mesma uma capacidade de dizer-se política, mostrar-se uma espécie de desafio à hegemonia tecnológica carrocêntrica. A resposta a essa pergunta parece ser positiva: sim uma bicicleta não é um carro! No horizonte saturado de automóveis, pedalar é um ato desafiador. Mas há que se fazer uma ressalva: no momento em que o cicloativismo logra mostrar o caráter contingencial do discurso dos carros, e o faz pedalando, usando o potencial político inscrito no objeto técnico, a resposta sistêmica é desvencilhar os carros de suas cadeias significantes, deslocá-los de um lugar central para uma posição obsoleta, passadista (responderia um hipotético enunciador liberal-capitalista: "Carro, eu? Como assim?"). Como diz Žižek (2012, p. 305): "Essa naturalização (ou apagamento) total da ideologia impõe uma conclusão triste, mas inevitável, a respeito da dinâmica social global contemporânea: hoje, o capitalismo é que é propriamente revolucionário".

Nesta leitura, o ciclismo é despotenciado, des-radicalizado, tirado do mundo da política, de certa forma silenciado, como somos todos na biopolítica, que segundo Žižek:

[...] designa essa constelação na qual os dispositivos não geram mais sujeitos ('interpelam os indivíduos nos sujeitos'), mas apenas administram e regulam a vida nua dos indivíduos; na biopolítica, somos todos homo sacer potenciais. Como é uma tendência do liberal-capitalismo global. (ŽIŽEK, 2012, p. 305)

A abertura de possíveis da política é rara, e sua duração depende de uma fidelidade ao evento (BADIOU, 1994). Sem esta, o que se tem é a própria reinvenção do sistema, que é típica das crises capitalistas que nunca cessam, mas que retornam como novas rodadas do próprio sistema. 
Heloisa Prates Pereira é professora da Escola de Comunicação do Centro Universitário FIAM-FAAM. É doutora em Comunicação e Semiótica da PUC-SP.

heloisapereira.hp@gmail.com

Vinicius Prates é professor dos cursos de Comunicação da Universidade Presbiteriana Mackenzie (UPM) e da Universidade Paulista (UNIP). É doutor em Comunicação e Semiótica pela PUC-SP.

viniciusprates.vp@gmail.com

\section{Referências}

AMOSSY, Ruth. Imagens de si no discurso: a construção do ethos. São Paulo: Contexto, 2005.

BADIOU, Alain. Para uma nova teoria do sujeito: conferências brasileiras. Rio de Janeiro: RelumeDumará, 1994.

São Paulo: a fundação do universalismo. São Paulo: Boteimpo, 2009.

BIKE é Legal. A professora bicicleta: dez lições de vida que a bike nos ensina. Por: Ricardo Gaspar. São Paulo: Bike é Legal, 2016. Disponível em: <http://bikeelegal.com/noticia/4289/a-professorabicliceta_-10-licoes-de-vida-que-a-bike-nos-ensina>. Acessado em: 15/05/2016.

CICLOCIDADE. Campanha 'Bicicleta faz bem ao comércio'. São Paulo: Ciclocidade, 2016. Disponível em <http://www.ciclocidade.org.br/>. Acessado em: 16/06/2016.

DELEUZE, Gilles. Conversações. 2a . Edição. São Paulo: Ed. 34, 2010.

FOUCAULT, Michel. O nascimento da biopolítica. São Paulo: Martins Fontes, 2008.

HEIDEGGER, Martin. Ensaios e conferências. $8^{a}$. Edição. Petrópolis: Vozes; Bragança Paulista: Editora Universitária São Franciso, 2012a.

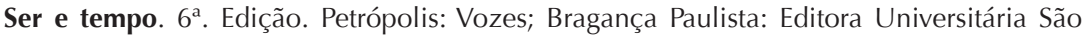
Francisco, 2012b.

LACLAU, Ernesto; MOUFFE, Chantal. Hegemonía y estrategia socialista: hacia una radicalización de la democracia. 2a edição. Buenos Aires: Fondo de Cultura Económica, 2004.

LAZARATO, Maurizio. Políticas del acontecimiento. Buenos Aires: Tinta Limón, 2006.

MANIFESTO dos Invisíveis. São Paulo: Bicicletada, 2008. Disponível em <http://bicicletada.org/ manifesto\%20dos\%20invis\%C3\%ADveis>. Acesso em 17/06/2016.

MIRANDA, José Carlos; TAVARES, Maria da Conceição. Brasil: estratégias de conglomeração. In. FIORI, José Luís (Org). Estados e moedas no desenvolvimento das nações. Petrópolis: Vozes, 1999.

PÊCHEUX, Michel. O discurso: estrutura ou acontecimento. $4^{\text {a }}$. Edição. Campinas (SP): Pontes, 2006.

PRADO, José L.A. et al. A invenção do Mesmo e do Outro na mídia semanal. DVD Hipermídia. São Paulo: PUC-SP, 2008. 
et al. Regimes de visibilidades em revistas. DVD. São Paulo: PUC-SP, 2011.

RANCIÈRE, Jacques. O desentendimento: política e filosofia. São Paulo: Editora 34, 1996.

TOLEDO, Benedito Lima de. São Paulo: três cidades em um século. São Paulo: Duas Cidades, 1983. Prestes Maia e as origines do urbanismo moderno em São Paulo. São Paulo: ABCP, 1996.

VAINER, Carlos. Pátria, empresa e mercadoria: notas sobre a estratégia discursiva do Planejamento Estratégico Urbano. In: ARANTES, Otília; VAINER, Carlos; MARICATO, Ermínia. A cidade do pensamento único: desmanchando consensos. 7ª. Edição. Petrópolis: Vozes, 2012.

ŽIŽEK, Slavoj. O espectro da Ideologia. In: ŽIŽEK, Slavoj (Org). Um mapa da ideologia. Rio de Janeiro: Contraponto, 1999.

Vivendo no fim dos tempos. São Paulo: Boitempo, 2012.

Texto recebido em julho e aprovado em outubro de 2016. 